\title{
Métodos de análise da composição química e valor nutricional de alimentos para
}

\section{ruminantes}

Methods of analysis of the chemical composition and nutritional value of ruminant feeds

Métodos de análisis de la composición química y del valor nutricional de los piensos para rumiantes

Chrislanne Barreira de Macêdo Carvalho

ORCID: https://orcid.org/0000-0003-0704-4949

Universidade Federal Rural de Pernambuco, Brasil

E-mail: chrislanne_carvalho@ @otmail.com

Gabriel Miranda Macambira

ORCID: https://orcid.org/0000-0002-0277-5286

Universidade Federal Rural de Pernambuco, Brasil

E-mail: gabriel.miranda.zootecnia@gmail.com

Ana Carolina Ferreira dos Santos

ORCID: https://orcid.org/0000-0003-0361-5222

Universidade Federal Rural de Pernambuco, Brasil E-mail: carolufrpe@hotmail.com

Helia Sharlane de Holanda Oliveira

ORCID: https://orcid.org/0000-0002-4314-4827

Universidade Federal Rural de Pernambuco, Brasil

E-mail: sharlaneho@yahoo.com

Dayane Albuquerque da Silva

ORCID: https://orcid.org/0000-0001-6243-3969

Universidade Federal Rural de Pernambuco, Brasil

E-mail: dayane.albuquerque.ds@gmail.com

Apolônio Gomes Ribeiro

ORCID: https://orcid.org/0000-0001-6730-0209

Universidade Federal Rural de Pernambuco, Brasil

E-mail: apoloniogomes962@gmail.com

Gabriela Duarte Silva

ORCID: https://orcid.org/0000-0001-9688-8881

Universidade Federal Rural de Pernambuco, Brasil

E-mail: gabrieladuarte1059127@gmail.com

Diana Valadares Pessoa

ORCID: https://orcid.org/0000-0002-1194-4985

Universidade Federal Rural de Pernambuco, Brasil

E-mail: dianavaladares13@hotmail.com

Marilene dos Santos Maciel

ORCID: https://orcid.org/0000-0003-4234-9764

Universidade Federal Rural de Pernambuco, Brasil

E-mail: marilenemaciel123@hotmail.com

Jéssica Berly Moreira Marinho

ORCID: https://orcid.org/0000-0002-3826-7670

Universidade Federal Rural de Pernambuco, Brasil

E-mail: jessicaberlymm@ gmail.com

Aurielle Silva Medeiros

ORCID: https://orcid.org/0000-0001-9388-6055

Universidade Federal Rural de Pernambuco, Brasil

E-mail: aurielle.medeiros@ufrpe.br

Géssica Solanna Calado Soares

ORCID: https://orcid.org/0000-0002-9066-0576

Universidade Federal Rural de Pernambuco, Brasil E-mail:gessicasolanna@hotmail.com

Tafnes Bernardo Sales

ORCID: https://orcid.org/0000-0002-2883-8433

Universidade Federal Rural de Pernambuco, Brasil

E-mail: tafnesbernardo@gmail.com

Pedro Henrique Ferreira da Silva

ORCID: https://orcid.org/0000-0002-0794-4499

Universidade Federal Rural de Pernambuco, Brasil E-mail: pehenrique1709@gmail.com

Gleyce Kelly de França Silva

ORCID: https://orcid.org/0000-0001-5595-4870 


\begin{abstract}
Resumo
A análise dos alimentos constitui um dos principais fatores observados na nutrição animal. A forma mais eficiente de identificação do teor de nutrientes dos alimentos, é através da composição química e valor nutritivo. Na quantificação analítica do valor nutritivo dos alimentos, os principais parâmetros utilizados são: matéria seca (MS), métodos de secagem em estufa, forno de micro-ondas e destilação com tolueno (silagens); matéria mineral (MM), método da incineração em altas temperaturas em mufla; proteína bruta $(\mathrm{PB})$ ou nitrogênio total $(\mathrm{N})$, método Dumas, Linder, Nessler, e Kjeldahl (padrão); fibra detergente neutro (FDN) e fibra detergente ácido (FDA), método Van Soest, com adaptações de equipamentos; lignina, método hidrólise ácida (padrão), com permanganato de potássio, Klason, e lignina solúvel em brometo de acetila; e digestibilidade, métodos in vivo, in situ, in vitro, e marcadores de digestibilidade. No entanto, estes podem ser onerosos, caros e demandar bastante tempo. Como método alternativo e indireto, tem-se a espectrometria de reflectância no infravermelho próximo (NIRS), que possui vantagens com custos, rapidez, usa um pequeno número de amostras e amostragem não destrutiva, é multiparamétrico, e não poluente. Considerando as diversas variáveis que podem ser utilizadas para determinação do valor nutritivo dos alimentos para ruminantes e a gama dos métodos analíticos disponíveis na literatura, cabe ao observador adotar aquele que melhor convém ao objetivo proposto, levando em consideração o tipo de alimento, custo, disponibilidade de reagentes, materiais, equipamentos, e animais à disposição. A metodologia adotada foi um estudo descritivo, resultando em uma revisão bibliográfica embasada em artigos científicos mundiais.
\end{abstract}

Palavras-chave: Alimentação; Digestibilidade; Metodologia; Van Soet.

\begin{abstract}
Feed analysis is one of the main factors observed in animal nutrition. The most efficient way to identify the nutrient content of foods is through the chemical composition and nutritive value. In the analytical quantification of the nutritive value of foods, the main parameters used are: dry matter (DM), oven drying, microwave oven, and toluene distillation methods (silages); mineral matter (MM), high temperature muffle incineration method; crude protein (CP) or total nitrogen (N), Dumas, Linder, Nessler, and Kjeldahl methods (standard); neutral detergent fiber (NDF) and acid detergent fiber (ADF), Van Soest method, with equipment adaptations; lignin, acid hydrolysis method (standard), with potassium permanganate, Klason, and acetyl bromide soluble lignin; and digestibility, in vivo, in situ, in vitro methods, and digestibility markers. However, these can be costly, expensive and time consuming. As an alternative and indirect method, there is the near infrared reflectance spectrometry (NIRS), which has advantages with costs, speed, uses a small number of samples and non-destructive sampling, is multiparametric, and non-polluting. Considering the many variables that can be used to determine the nutritive value of ruminant feed and the range of analytical methods available in the literature, it is up to the observer to adopt the one that best suits the proposed objective, taking into account the type of feed, cost, availability of reagents, materials, equipment, and animals at disposal. The methodology adopted was a descriptive study, resulting in a literature review based on worldwide scientific articles.
\end{abstract}

Keywords: Feeding; Digestibility; Methodology; Van Soet.

\title{
Resumen
}

El análisis de los piensos es uno de los principales factores observados en la nutrición animal. La forma más eficaz de identificar el contenido en nutrientes de los alimentos es a través de la composición química y el valor nutritivo. En la cuantificación analítica del valor nutritivo de los alimentos, los principales parámetros utilizados son: materia seca (MS), métodos de secado al horno, horno microondas y destilación con tolueno (ensilajes); materia mineral (MM), método de incineración a altas temperaturas en horno de mufla; proteína bruta $(\mathrm{PB})$ o nitrógeno total $(\mathrm{N})$, métodos Dumas, Linder, Nessler y Kjeldahl (estándar); fibra detergente neutra (FDN) y fibra detergente ácida (FDA), método Van Soest, con adaptaciones del equipo; lignina, método de hidrólisis ácida (estándar), con permanganato potásico, Klason, y lignina soluble en bromuro de acetilo; y digestibilidad, métodos in vivo, in situ, in vitro, y marcadores de digestibilidad. Sin embargo, estos pueden ser costosos, caros y llevar mucho tiempo. Como método alternativo e indirecto, existe la espectrometría de reflectancia en el infrarrojo cercano (NIRS), que presenta ventajas en cuanto a costes, rapidez, utiliza un número reducido de muestras y un muestreo no destructivo, es multiparamétrica y no contaminante. Teniendo en cuenta las diversas variables que pueden utilizarse para determinar el valor nutritivo de los alimentos para rumiantes y la gama de métodos analíticos disponibles en la literatura, corresponde al observador adoptar el que mejor se adapte al objetivo propuesto, teniendo en cuenta el tipo de alimento, el coste, la disponibilidad de reactivos, los materiales, el equipo y los animales de que dispone. La metodología adoptada fue un estudio descriptivo, que dio lugar a una revisión bibliográfica basada en artículos científicos de todo el mundo.

Palabras clave: Alimentación; Digestibilidad; Metodología; Van Soet. 


\section{Introdução}

A análise de alimentos constitui área relevante no ensino das ciências que estudam os alimentos, pois fornece ferramentas e subsídios para vários segmentos do controle de qualidade, do processamento e do armazenamento dos alimentos processados, sendo um dos principais pontos a serem observados na nutrição animal (Detmann et al., 2012).

O conhecimento do valor nutritivo de um determinado alimento utilizado na nutrição animal, além de ser a forma mais eficiente de identificarmos o teor de nutrientes, é também condição básica para a adoção de práticas de manejo que visam aumentar a produção animal (Genro \& Orqis, 2009). De acordo Gonçalves et al. (2009) e Salman et al. (2010), os alimentos usualmente podem ser classificados segundo os teores de fibra bruta (FB) e proteína bruta (PB), como alimentos volumosos, concentrado proteico e concentrado energético. Alimentos com acima de 18\% de FB são considerados volumosos, como as pastagens nativas e cultivadas, forragens e silagens. Por sua vez, os alimentos concentrados possuem menos de $18 \%$ de FB, sendo rotulados como: concentrado proteico, apresentando acima de $20 \%$ de PB, por exemplo, o farelo de soja, de algodão, de girassol, etc.; e, concentrados energéticos com menos de $20 \%$ de PB, como sorgo, milho, etc.

Fontaneli et al. (2012) referem-se ao valor nutritivo como composição química dos nutrientes dos alimentos e a digestibilidade destes, constituindo um importante componente da qualidade dos alimentos. Já a qualidade do alimento pode ser expressa em relação à produção por animal, quando a disponibilidade do alimento e potencial do animal não são limitantes. Portanto, o resultado de uma análise química torna-se uma importante ferramenta para o balanceamento correto da dieta dos animais, com maiores respostas na produção de leite e carne (Serafim et al., 2017).

Na quantificação analítica do valor nutritivo dos alimentos, são utilizados vários parâmetros, como matéria seca (MS), matéria mineral $(\mathrm{MM})$, proteína bruta $(\mathrm{PB})$ ou nitrogênio total $(\mathrm{N})$, fibra detergente neutro (FDN), fibra detergente ácido (FDA), lignina, digestibilidade, entre outros. Para determinação desses parâmetros os métodos mais utilizados são: a análise centesimal ou proximal de Weende (1864), o sistema de nutrientes digestíveis totais (NDT), proposto por Henry e Morrison (1910), o método de Van Soest (1964), e os métodos biológicos de digestibilidade, que podem ser diretos como a digestibilidade in vitro com a técnica de dois estágios, de acordo com Tilley e Terry (1963), a técnica da digestibilidade verdadeira in vitro proposto por Van Soest (1994), produção de gás in vitro (Theodorou et al., 1994), digestibilidade aparente in vivo, e também os métodos indiretos in situ, além do uso de indicadores internos e externos.

Os métodos tradicionais que objetivam determinar a composição química dos alimentos têm sido amplamente utilizados em laboratórios de todo o mundo, no entanto, são na sua grande maioria, onerosos, caros e demandam muito tempo. Como método alternativo e indireto, tem-se a espectrometria de reflectância no infravermelho próximo (NIRS - Near Infra Red System), que usa o princípio da emissão de radiação eletromagnética. O NIRS tem sido relatado como um método para avaliar a composição química de produtos agrícolas, alimentos e forragens (AOAC, 1990; Fontaneli et al., 2002; Philips et al., 2007; Gindri et al., 2019;), e possui algumas vantagens sobre as análises químicas tradicionais, como a realização de análises custo-efetivas, rápidas, utilizam amostragem não destrutiva e pequeno número de amostras, é multiparamétrico, além de não ser poluente ao meio ambiente por não utilizar reagentes (Arzani et al., 2015).

Na determinação do valor nutricional, geralmente, utiliza-se o valor médio dos dados obtidos a partir de várias metodologias analíticas. Porém, a variabilidade das médias obtidas pode ser devido as variações nos métodos de coleta, processamento e análises empregadas nos diversos laboratórios, ou por diferenças reais existentes nas diferentes amostras (Rech et al., 2010). Em função disso, devem ser realizadas avaliações integradas em relação à precisão e exatidão dos métodos em detectar variações no valor nutritivo de dietas para ruminantes (Silveira et al. 2009). Neste contexto, objetivou-se com esse estudo, fazer um levantamento teórico acerca dos métodos de análise da composição química e valor nutricional de alimentos para animais ruminantes. 


\section{Metodologia}

O presente estudo trata-se de uma revisão narrativa acerca dos Métodos de análise da composição química e valor nutricional de alimentos para ruminantes. A revisão abrangeu, em sua maioria, artigos científicos, mas foram também utilizadas teses e dissertações presentes na base de dados do Scielo (Scientific Eletronic Library Online), Science Direct e Google Acadêmico. Descartou-se trabalhos sem resumo e que não abordavam a temática do estudo, assim como aqueles que apresentavam metodologias mal aplicadas ou suspeitas.

\section{Revisão de literatura}

\subsection{Valor nutritivo dos alimentos para ruminantes}

O valor nutritivo do alimento é definido como uma medida de sua capacidade em sustentar grupos de atividades metabólicas inerentes ao organismo animal (Blaxter, 1956). Por meio do conceito de eficiência total de utilização de alimentos descrito por Brody (1945) e Kleiber (1975), a relação entre valor nutritivo e o desempenho biológico pode ser igual à massa de produto obtida (carne, leite, lã) sobre o consumo alimentar, durante o tempo necessário para a sua síntese pelo animal (Rodrigues \& Vieira, 2011).

Na determinação do valor nutricional de um alimento, por exemplo uma espécie forrageira, é necessária a realização de estudos que permitam a avaliação conjunta da composição química (MS, MO, PB, EE, FDN, FDA e lignina), digestibilidade e constituintes secundários que podem interferir na ingestão e utilização da forragem consumida pelos ruminantes (Figura 1).

Figura 1. Fatores associados ao valor nutritivo da forragem.

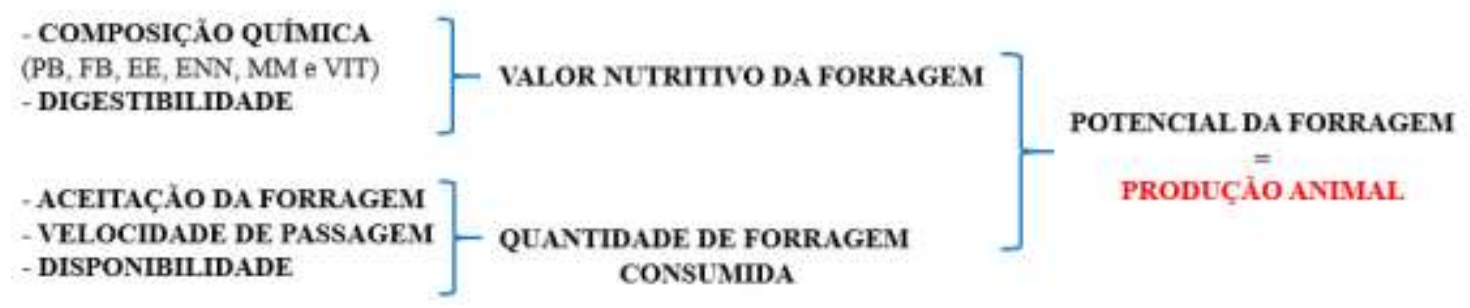

Fonte: Mott e Moore (1970).

Campos et al. (2010) avaliaram a composição química, digestibilidade e consumo animal em alguns alimentos para ruminantes (Tabela 1). Constatou-se que os animais alimentados com as silagens de capim-elefante, de milho e de sorgo, consumiram maiores quantidades de MS, PB, EE e FDN, em relação aos alimentados com cana-de-açúcar. Os maiores consumos de nutrientes obtidos com as dietas à base de silagens, provavelmente, tenham ocorrido em razão da maior digestibilidade dos mesmos. Além disso, as digestibilidades aparentes da MS não diferiram entre os alimentos.

Vale ressaltar que, as diversas transformações morfológicas pelas quais as plantas passam durante o seu desenvolvimento fenológico, alteram sua composição química e consequentemente a sua digestibilidade (Fontaneli et al., 2012). Isso tudo porque, Segundo Van Soest (1994), com o crescimento da forragem, ocorrem alterações a nível de tecidos, que resultam na elevação dos teores de compostos estruturais (celulose, hemicelulose e lignina) e diminuição de conteúdo celular (carboidratos solúveis, proteína, minerais e vitaminas), consequentemente reduzindo a digestibilidade. Fatores como fertilidade do solo, adubações realizadas, bem como as condições climáticas, também influenciam no valor nutritivo das forrageiras (Farias et al., 2015). Além disso, a digestibilidade ainda pode ser influenciada por características do alimento, do animal e das situações de alimentação (Mertens, 1993). 
Tabela 1. Composição química, digestibilidade aparente e consumo da cana-de-açúcar, das silagens de capim-elefante, de milho e de sorgo.

\begin{tabular}{lcccc}
\hline & \multicolumn{3}{c}{ Alimentos } \\
\cline { 2 - 5 } Itens $^{1}$ & Cana-de-açúcar & Silagem de capim-elefante & Silagem de milho & Silagem de sorgo \\
\hline MS (\%) & 25,77 & 23,23 & 34,84 & 24,59 \\
MO $^{2}$ & 98,25 & 94,18 & 94,29 & 93,18 \\
PB $^{2}$ & 2,79 & 6,29 & 7,06 & 4,93 \\
FDN $^{2}$ & 48,97 & 74,23 & 57,12 & 32,18 \\
FDA $^{2}$ & 23,67 & 45,39 & 26,72 & 5,40 \\
Lignina $^{2}$ & 4,85 & 8,61 & 5,17 & $59,55 \mathrm{a}$ \\
Digestibilidade aparente da & $54,69 \mathrm{a}$ & $55,35 \mathrm{a}$ & $60,60 \mathrm{a}$ & \\
MS (\%) & & & & $1212,16 \mathrm{a}$ \\
Consumo de MS (g/dia) & $726,33 \mathrm{~b}$ & $990,21 \mathrm{a}$ & & $1054,96 \mathrm{a}$ \\
\hline
\end{tabular}

${ }^{1} \mathrm{MS}$ - Matéria Seca, \%; MO - matéria orgânica; PB - proteína bruta; FDN - fibra em detergente neutro; FDA - fibra em detergente ácido; ${ }^{2}$ valores expressos em \% da matéria seca; Valores seguidos por letras diferentes, na mesma linha, diferem significativamente $(\mathrm{P}<0,05)$, pelo teste de Student-Newman-Keuls. Fonte: Adaptado de Campos et al. (2010).

A digestibilidade aparente é a proporção do alimento ingerida que não foi excretada nas fezes. O termo aparente é utilizado quando não se considera a matéria seca fecal metabólica, que é representada, principalmente, pelas perdas endógenas, descamação epitelial e contaminação por microrganismos nas fezes. Quando se desconta a perda de matéria fecal metabólica, obtém-se a digestibilidade verdadeira dos alimentos, valor este sempre superior à digestibilidade aparente (Berchielli et al., 2011).

Já o consumo, é um dos aspectos mais importantes na nutrição de ruminantes, pois dele vai depender à entrada dos nutrientes ofertados aos animais, determinando, desta forma, o desempenho dos mesmos, sendo regulado e limitado por fatores metabólicos e fisiológicos (Van Soest, 1994). Ainda de acordo com esses pesquisadores, o consumo alimentar pode variar em função da variabilidade animal (espécie, nível nutricional, categoria, demanda energética, idade e sexo), da aceitabilidade e seleção de forragem.

Como vimos, muitas são as fontes que determinam o valor nutricional de determinado alimento. No Brasil, as informações sobre o valor nutritivo acerca da imensa variedade de alimentos utilizados para animais, estão em pleno desenvolvimento, e encontram-se disponíveis na literatura (Campos et al., 2010; Ortega-Aguirre et al., 2015; Pazdiora et al., 2019).

\subsection{Métodos para a avaliação do valor nutritivo dos alimentos para ruminantes}

\subsubsection{Obtenção, coleta e processamento de amostras}

Para a realização de uma análise é necessária a realização da amostragem, que tem por finalidade a obtenção da amostra química e fisicamente representativa do material a ser avaliado (Silva \& Queiroz, 2005).

A amostragem é o conjunto de operações com os quais se obtém, do material em estudo, uma porção relativamente pequena, de tamanho apropriado para o trabalho no laboratório, mas que ao mesmo tempo represente corretamente todo o conjunto da amostra. A quantidade de amostra tomada para realização da análise é relativamente pequena em comparação com a amostra total, devendo compreender de 5 a $10 \%$ do peso total do alimento a ser analisado (Cecchi, 2003)

O método de coleta varia de acordo com o tipo de alimento que será analisado (pasto, silagens e fenos, grãos e farelos, ração, etc). Porém, em todos os casos, a amostra deve sempre estar muito bem identificada, com data de coleta, lote a que 
pertence, estágio fenológico em que foi coletada (no caso de plantas forrageiras), procedência, e conter informações sobre que tipo de análises deverá ser realizadas (Genro \& Orqis, 2009). O ideal é analisar as amostras frescas o mais rápido possível. Mas quando as análises não puderem ser processadas de imediato, é necessário que as amostras sejam congeladas para melhor conservação e evitando assim, o aparecimento de microrganismos, mantendo a composição química das amostras obtidas, além do congelamento pode-se promover a secagem parcial das amostras em estufa com circulação forçada de ar à $55^{\circ} \mathrm{C}$, para evitar a perda de compostos voláteis e alterações químicas de outros componentes das amostras, permitindo o armazenamento seguro dos alimentos e maior facilidade no processamento mecânico (Rech et al., 2010; Detmann et al., 2012). É importante salientar que este processo de secagem das amostras também pode ser realizado por processo de liofilização, ou seja, a água é removida da amostra congelada por sublimação (Detmann et al., 2012).

Após a secagem dos alimentos, deve-se haver a adequação das amostras para a análise a qual serão submetidas, através do processamento físico da amostra, para a padronização da superfície específica do alimento, promovendo melhor homogeinização das amostras. Esse processo geralmente envolve a secagem e moagem (Silva \& Queiroz, 2005; Detmann et al., 2012).

\subsubsection{Composição química de alimentos determinadas em laboratórios}

Para a determinação da composição química dos alimentos, são mais utilizados basicamente dois métodos de análise, que são a análise centesimal ou proximal de Weende (1864) e o método de Van Soest (1964) (Figura 2).

O método de Weende foi desenvolvido por Stohmann e Henneberg, entre 1860 e 1864, na estação experimental de Weende, na Alemanha. Este método é o mais utilizado para se conhecer a composição química aproximada dos alimentos, e separa o alimento em frações que contém substâncias que apresentam alguma propriedade em comum Através do método de análise aproximativa de Weende, são determinados seis grandes componentes químicos dos alimentos forrageiros (Figura 2): matéria seca, matéria mineral, proteína bruta, extrato etéreo, fibra bruta e extrato não nitrogenado. As técnicas são parecidas com as originais, com exceção do nitrogênio, que é determinado pelo método Kjeldahl (AOAC, 1990).

O método de determinação dos componentes fibrosos das forrageiras proposto por Van Soest (1964) é baseado na separação das diversas frações constituintes das forrageiras, por meio de reagentes específicos, denominados detergentes. A partir de uma amostra de alimento, a matéria seca é dividida em conteúdo celular (fração solúvel da célula vegetal) e parede celular (fração insolúvel) (Genro \& Orqis, 2009). 
Figura 2. Métodos para determinação da composição química dos alimentos.

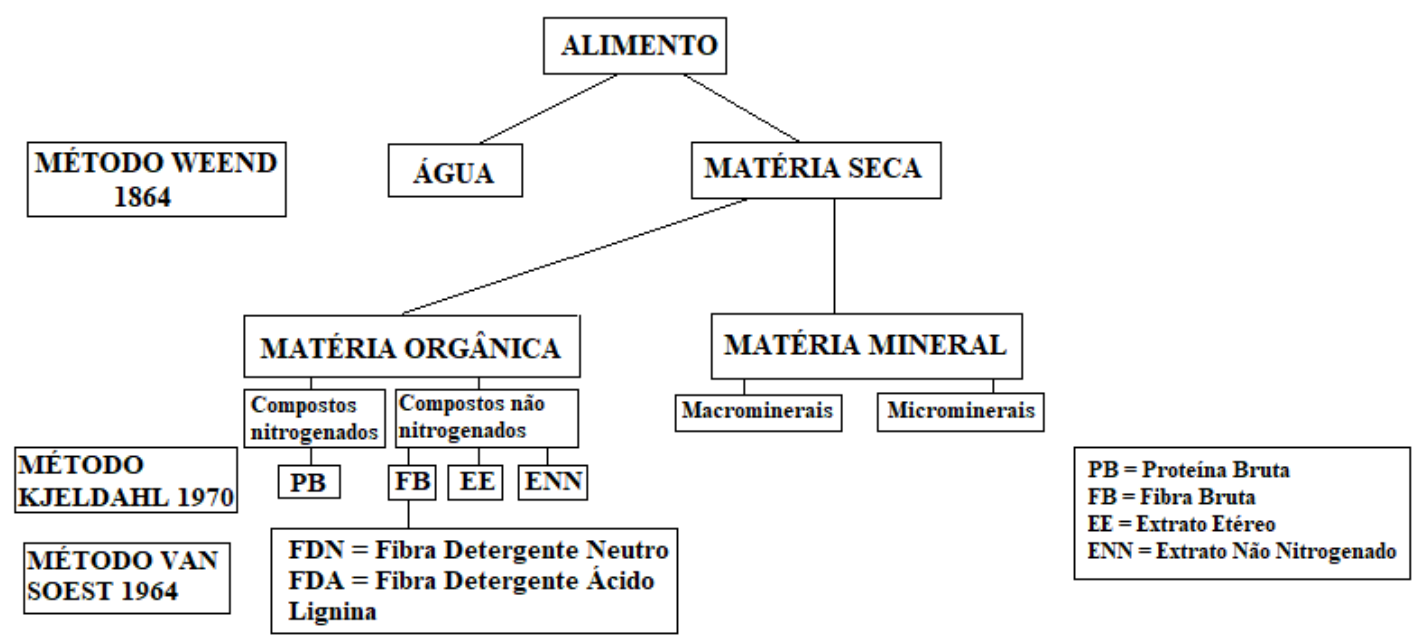

Fonte: Adaptado de Grana (2014).

\subsubsection{Matéria Seca}

A matéria seca (MS) é toda fração do alimento excluída a água ou umidade natural (Salman et al., 2010). Sua determinação é ponto de partida da análise dos alimentos, e é de grande importância, uma vez que a preservação do alimento pode depender do teor de umidade presente no material (Silva \& Queiroz, 2005; Genro \& Orqis, 2009). Além disso, é requerida para estimar as quantidades de nutrientes presentes no alimento, os quais são expressos na base seca por ser uma medida padronizada (Detmann et al., 2012).

Os métodos convencionais, segundo Silva e Queiroz (2005), para a remoção da umidade da amostra, são pela secagem em estufa com circulação forçada de ar à temperaturas de $55^{\circ} \mathrm{C}$ por 16 a 48 horas (pré-secagem) dependendo do teor de umidade do alimento a se analisar, após procede-se a secagem definitiva a $135{ }^{\circ} \mathrm{C}$ por duas horas, ou $100{ }^{\circ} \mathrm{C}$ por 24 horas, ou $105{ }^{\circ} \mathrm{C}$ por 16 horas. Para alimentos como grãos, farelos, tortas e rações usam-se somente a secagem definitiva (Rech et al., 2010).

Contudo, muitas vezes não é possível dispor de tal equipamento, o que ocorre com frequência a campo. Por isso, muitos pesquisadores tem utilizado o forno micro-ondas (FMO) em seus estudos para este fim (Lacerda et al. 2009; Serafim et al., 2017; Bueno et al., 2017). E ao se comparar o processo de secagem em forno micro-ondas e em estufa de ventilação forçada de ar, sobre os efeitos na composição química, estes pesquisadores relataram que o uso do FMO pode ser uma alternativa mais rápida para obtenção de MS dos alimentos, mostrando eficiência semelhante ao método de secagem em estufa com circulação de ar.

Oliveira et al. (2015) também compararam métodos de determinação de umidade utilizando o método padrão em estufa e forno de micro-ondas convencional, em diferentes cactáceas empregadas na alimentação animal. Foram utilizadas amostras vegetais de palma forrageira (Opuntia ficus-indica Mill), mandacaru (Cereus jamacaru DC), facheiro (Pilosocereus pachycladus Ritter.) e xiquexique [Pilosocereus gounellei (A. Weber ex K. Schum.) Byl ex Rowl.]. As amostras foram cortadas com faca de aço inox em pedaços de aproximadamente $1 \mathrm{~cm}$ e trituradas em liquidificador doméstico até obtenção de uma mucilagem. Os teores de água determinados pelos dois métodos nas amostras das cactáceas trituradas foram relativamente próximos.

Outros métodos para determinação da umidade são citados na literatura, como a destilação com tolueno (AOAC, 1990; Silva \& Queiroz, 2005), que é recomendado para forragens fermentadas (silagens) que contenha altos conteúdos de 
substâncias voláteis. O princípio básico é de que a água é desprendida (destilada) da amostra e capturada sob camada de tolueno. Neste caso, determina-se a quantidade da água diretamente.

\subsubsection{Matéria Mineral}

A matéria mineral (MM) ou cinzas, é constituída pelo resíduo inorgânico obtido após a queima da matéria orgânica, a qual é convertida em $\mathrm{CO}_{2}, \mathrm{H}_{2} \mathrm{O}$ e $\mathrm{NO}_{2}$, e eliminada em conjunto com as substâncias voláteis decompostas pelo calor (Souza et al., 2017). O método consiste basicamente na incineração do alimento em altas temperaturas (normalmente de 500 a $600^{\circ} \mathrm{C}$ ), por tempo suficiente para que ocorra combustão total da matéria orgânica (Silva \& Queiroz, 2005).

A porcentagem da MM, fornece apenas uma indicação da riqueza em elementos minerais da amostra (Silva \& Queiroz, 2005; Genro \& Orqis, 2009). São determinadas, muitas vezes, apenas para se conhecer o extrato não-nitrogenado (ENN) e/ou a matéria orgânica (Silva \& Queiroz, 2005).

Geralmente, as metodologias para determinação de MM não se diferem do método da AOAC (1990). Ainda assim, Souza et al. (2017), conduziram um estudo colaborativo para avaliação do teor de MM em alimentos em sete laboratórios de análise de alimentos. Eles evidenciaram diferenças entre procedimentos de avaliação de MM em função dos diferentes laboratórios. Dentre elas: as massas de amostras utilizadas nas avaliações ( 1 a $5 \mathrm{~g}$ ); relação da amostra e o volume do cadinho ( $\left.\mathrm{mg} \mathrm{cm}{ }^{-3}\right)$; preparação do cadinho (limpeza e secagem); temperaturas e o tempo de queima $\left(550^{\circ}\right.$ a $600^{\circ} \mathrm{C}$ e 3 a 4 horas, respectivamente); forma de resfriamento da mufla (fechada ou parcialmente aberta); e temperatura da retirada do cadinho. Com isso, os teores de MM estimados pelos laboratórios participantes deste estudo apresentaram baixa reprodutibilidade, o que é agravado pela presença de efeito de interação do material avaliado e do laboratório.

Gindri et al. (2019) comparando métodos para estimar os teores de MO digestível de dietas ingeridas por ovinos, determinaram o teor de $\mathrm{MM}$ queimando as amostras a $600^{\circ} \mathrm{C}$ por três horas, e a MO por diferença de massa. Bem como utilizaram a técnica de espectroscopia de reflectância de infravermelho próximo (NIRS). Os autores produziram resultados semelhantes e confiáveis entre as metodologias.

\subsubsection{Proteína Bruta}

Proteína é um dos nutrientes fundamentais para a nutrição dos animais (Serafim et al., 2017). Proteína bruta (PB) é um termo que envolve um grande grupo de substâncias com estruturas semelhantes, porém com funções fisiológicas muito diferentes. A análise de PB é baseada no fato de as proteínas vegetais terem porcentagem de nitrogênio quase constante, em torno de $16 \%$, o que se faz é determinar o nitrogênio e, por meio de um fator de conversão $(100 / 16=6,25)$, transformar o resultado em proteína bruta (Silva \& Queiroz, 2005; Genro \& Orqis 2009; Rech et al., 2010; Detmann et al., 2012).

Há vários métodos para a análise do teor de nitrogênio dos alimentos, sendo o método clássico, inicialmente descrito por Dumas em 1837. Neste processo de digestão seca ou combustão, o nitrogênio contido no material é transformado em nitrogênio gasoso e a medição do gás realizada por meio de nitrômetro (Silva \& Queiroz, 2005). Este método de Dumas apresenta como principal vantagem a rapidez na análise por amostra e desvantagens quando relacionado ao alto custo inicial para aquisição do equipamento e as calibrações do aparelho (Keeney \& Bremner, 1967).

Existe o método de Linder, no qual faz a mineralização da amostra com uma mistura de $\mathrm{H}_{2} \mathrm{SO}_{4}+\mathrm{H}_{2} \mathrm{O}$ a $30 \%$, e o nitrogênio é transformado em uma forma amoniacal (Reche et al., 2010). E o método de Kjeldahl, que é o mais utilizado nos dias atuais (padrão).

E ainda o método de Nessler, proposto por Julius Nessler em 1856, sendo o primeiro método colorimétrico para a determinação de amônia em extrato ácido digerido anteriormente, e depois este extrato reage com o reagente de Nessler que é uma solução alcalina de iodeto de mercúrio em iodeto de potássio (Malavolta et al., 1997). O método possui vantagens por ser 
rápido e simples, porém tem pouca repetibilidade e não é sensível a baixas concentrações de amônia. O reagente de Nessler não é estável e não deve ser estocado por longo tempo. Nesta metodologia a tempo de reação, a quantidade de reagente, a temperatura da reação durante o desenvolvimento de cor, a presença de alguns cátion e ânions, e o pH da reação são fatores críticos para desenvolvimento da cor.

Uma desvantagem do método de Kjeldahj é a utilização de uma grande quantidade de produtos químicos que é liberado no meio ambiente. Com o objetivo de diminuir a quantidade de resíduos gerados e, consequentemente, custos, Galvani e Gaertner (2006) propuseram em seus estudos, uma adequação do método de Kjeldahl a partir da redução na quantidade de cada reagente utilizado durante o processo para a determinação do nitrogênio total. A determinação do nitrogênio total e proteína bruta foram realizadas pelo processo de digestão Kjeldahl conforme metodologia atual adotada pela Embrapa e descrita no Manual de Laboratórios: Solo, Água, Nutrição Animal e Alimentos (Nogueira \& Souza, 2005), porém a quantidade de amostra e de cada reagente utilizado para o estudo da adequação da metodologia foram reduzidos. As alterações nas quantidades dos reagentes proposta pela metodologia em estudo não influenciaram significativamente nos resultados de PB e apresentaram precisão compatível com a metodologia atualmente utilizada.

Em contrapartida, Philips et al. (2007) compararam a estimativa da concentração de PB de pastagens de capimbermuda derivadas de sensoriamento remoto (SR) da biomassa verde em pé, usando medidas de reflectância espectral, e aquelas derivadas da análise por espectroscopia de reflectância no infravermelho próximo (NIRS) de amostras fecais. Os métodos SR e NIRS sinalizaram que a PB caiu abaixo de 7\% no mesmo ponto na estação de pastejo. Com isso, eles concluíram que o SR e o NIRS fornecem boas estimativas da concentração de PB da forragem.

\subsubsection{Fibra em Detergente Neutro e Fibra em Detergente Ácido}

O conceito de fibra bruta (FB) foi estabelecido há mais de um século por Weende (AOAC, 1990). A fibra é a porção da matéria seca insolúvel em ácidos e álcali. Possui em sua constituição principalmente celulose, hemicelulose e lignina, (Genro e Orqis, 2009).

Várias técnicas analíticas estão disponíveis para a caracterização da fração de fibra. O método mais antigo e ainda aplicado na área da nutrição de não ruminantes é o método da fibra bruta (método de Weende). Mas devido à solubilização substancial de polissacarídeos estruturais e lignina, essa variável mede apenas uma fração incompleta e variável dos componentes fibrosos de carboidratos. A abordagem dos detergentes, desenvolvidas por Van Soest (1964) e por Van Soest e Wine (1968) para a análise de forragens ricas em fibras, é atualmente aplicada com mais frequência para análise de fibras em alimentos para ruminantes, pois fornece uma análise mais satisfatória para melhor caracterizar os carboidratos da parede celular vegetal.

Nesta abordagem, as frações da fibra que são insolúveis em detergentes neutros (FDN) ou em detergentes ácidos (FDA) são medidas, e o resíduo após o tratamento da fração FDA são digeridas com ácido sulfúrico a $12 \mathrm{~mol} / \mathrm{L}$, sendo o resíduo obtido considerado como lignina em detergente ácido (LDA). Por diferença, hemicelulose (FDN - FDA) e celulose (FDA - LDA) são calculadas (Hindrichsen et al., 2006). No entanto, foi relatado que os polissacarídeos extraíveis em água e pectinosos são solúveis em detergente neutro e que o amido e a proteína podem contaminar o resíduo de FDN. Então, Van Soest et al. (1991) sugeriram a adição de $\alpha$-amilase e sulfito de sódio para evitar essa contaminação com amido e proteína, respectivamente.

Existem alguns tipos de $\alpha$-amilase no mercado. Neste aspecto, Bortolassi et al. (2000), avaliaram duas enzimas: $\alpha$ amilase Termamil 120 L (Novonordisc Bio Ind. do Brasil Ltda/Araucária - PR) e Alpha - Amylase heat stable (Ankom Technology Corporation/NY - USA). Essas duas enzimas foram avaliadas no método convencional, para análise de FDN, 
onde os alimentos testados não apresentaram diferenças quanto aos teores de FDN. Desse modo, optou-se por utilizar a $\alpha$ amilase Termamil $120 \mathrm{~L}$ devido ao menor custo e à maior disponibilidade desse produto no mercado nacional.

Van Soest et al. (1991) recomendam que as análises de fibras sejam sempre realizadas sequencialmente em forragens com alto teor de pectina, mas a magnitude do erro potencial, se isso não for feito, não está muito bem documentada. Cassida et al. (2007), compararam a análise sequencial e não sequencial das fibras com e sem correção para cinzas residuais de detergente ácido em forragens ricas em pectina. Eles constataram que a análise sequencial de fibras com correção para cinzas residuais foi requerida para leguminosas forrageiras com alto teor de pectina e leguminosas sem taninos, mas o método não-sequencial foi aceitável apenas para gramíneas.

Entre as metodologias para análise de fibra em detergente, uma técnica automatizada do Filter Bag foi introduzida pela Ankom Technology (Macedon, NY; Komarek, 1993). De acordo com Berchielli et al. (2001), o método Filter Bag é uma técnica que foi lançada no mercado afim de minimizar a mão de obra, pois alguns dos procedimentos que são realizados pelo método convencional proposto por Van Soest (1964) para determinação da FDN e FDA das forrageiras, como as lavagens e filtragens dos cadinhos porosos, podem ser realizados diretamente no aparelho tipo Ankom®, por meio da utilização de filtros chamados F57 (saquinhos). Os alimentos são alocados dentro dos filtros F57 os quais são fixados em ambientes fechado dentro do aparelho tipo Ankom ${ }^{\circledR}$, o que garante uma boa homogeneização das amostras além de facilitar e agilizar um maior número de amostra por dia em relação ao método convencional.

No entanto, os filtros F57 utilizados no aparelho de Ankom® apresentam ao alto custo, e os mesmos são obtidos na própria empresa fabricante do equipamento, o que muitas vezes impossibilitando a realização das análises. Logo Berchielli et al. (2001) comparam os valores de FDN e FDA obtidos com o equipamento da Ankom® e pelo método convencional (Van Soest), e testaram quatro tipos de saquinhos para filtragem de amostra (SPA - saquinho de papel Ankom®, SNA - saquinho de náilon Ankom ${ }^{\circledR}, \mathrm{SNN}$ - saquinho de náilon novo e SNU - saquinho de náilon usado) (Figura 3) em diferentes materiais. Constatou-se que não houve diferença entre os valores de FDN e FDA, obtidos pelo equipamento Ankom® ou pelo convencional, para os alimentos estudados, com exceção da polpa cítrica. Todavia, os tipos de saquinhos de filtragem utilizados, não influenciaram os teores de FDN nos diferentes alimentos, salvo as fezes, dos quais os saquinhos de náilon resultaram em concentrações de FDN inferiores.

Em contrapartida, Hristov et al. (2010) avaliaram a variabilidade nas análises de FDN tratada com amilase em amostras de ração e amostras de ração mista total entre laboratórios comerciais de análise de ração. A única variação na metodologia usada com consistência suficiente para a análise estatística foi a técnica do cadinho para FDN (Mertens, 2002) e a técnica do Filter Bag com base no uso do analisador de fibra da Ankom®. Eles constataram variabilidade significativa na análise de FDN dos alimentos individuais entre os laboratórios participantes. No entanto, os laboratórios que usam a técnica do Filter Bag tendem a produzir resultados mais variáveis do que os laboratórios que usam a técnica do cadinho. Os resultados deste estudo enfatizaram a necessidade de os laboratórios de análise de alimentos seguirem exatamente o método oficial da análise de FDN.

Raffrenato e Van Amburgh (2011) também propuseram aprimorar a metodologia de Van Soest (1964), utilizando filtro de microfibra de vidro com tamanho de poro de 1,5 $\mu \mathrm{m}$ [filtro 934-AH de Whatman (Whatman Limited; Whatman, 2009)], sem filtro ou com o filtro de vidro, em forrageiras e amostras de fezes, analisadas sequencialmente para FDA e LDA. Eles relataram que com o uso do filtro, os valores médios de FDA aumentaram 4,2\% e os valores médios de LDA aumentaram $18,9 \%$. No geral, os valores de FDA e LDA foram maiores com o uso do filtro de microfibra de vidro, indicando que, conforme o tipo de amostra analisada mudava. O uso do cadinho de Gooch sem o auxiliar de filtragem resulta em perda de partículas. 
Outro método alternativo para avaliar o teor de FDN e de FDA dos alimentos é o método da EMBRAPA, desenvolvido por Souza et al. (1999), que consiste numa simplificação analítica dos procedimentos originais. Geron et al. (2014), avaliaram o teor de FDN e FDA diferentes forrageiras, obtidos por três procedimentos diferentes, sendo o método convencional, o Filter Bag Technique da Ankom ${ }^{\circledR}$ e o adaptado pela EMBRAPA. Eles concluíram que o teor da FDN e FDA das forrageiras do estudo em questão, podem ser determinados pelo procedimento adaptado pela EMBRAPA, uma vez que este não diferiu em relação a metodologia convencional e a do Filter Bag Technique da Ankom®, além de apresentar menor gasto de reagentes e consequentemente menor custo.

Já Farias et al. (2015) compararam equipamentos e tecidos alternativos na determinação de FDN e FDA, com o método convencional. Neste estudo, foram utilizados dois tecidos, sendo o náilon $(50 \mu \mathrm{m})$ e tecido não tecido (TNT, 100g m²), e dois equipamentos, o digestor de fibra (Marconi MA444/CIß) e a autoclave para determinação dos teores de FDN e FDA, comparado com o convencional. O procedimento de digestão da fibra por meio do aparelho autoclave difere do procedimento do equipamento digestor de fibra pela presença da pressão das válvulas do aparelho autoclave. Como conclusão, o teor de FDN independente do equipamento utilizado, e o teor de FDA obtido no equipamento digestor de fibra, ambos com o tecido náilon, são semelhantes ao método convencional.

Figura 3. Malhas dos diferentes saquinhos utilizados na digestão de fibra com o aparelho Ankon®, vistas através de microscopia eletrônica (aumento de 75x). No detalhe aumento de 500x.

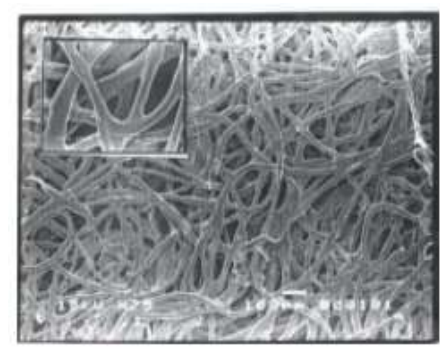

Saquinho de papel ANKOM (SPA) Pattem bags ANKOM (PBA)

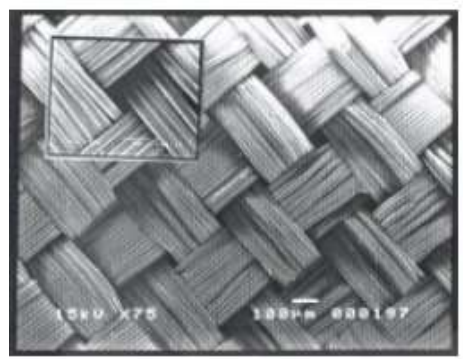

Saquinho de náilon novo (SNN) New nalton Bag (NBB)

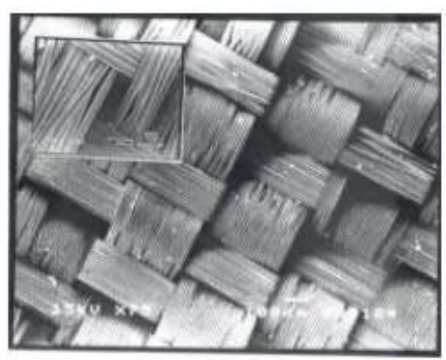

Saquinho de nálion ANKOM (SNA) Nailon bags ANKOM (NBA)

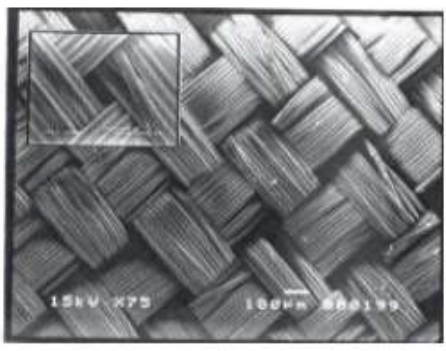
Saquinho de náilon usado (SNU)
Used nailon beg (UNB)

Fonte: Berchielli et al. (2001)

\subsubsection{Lignina}

A lignina é um metabólito polifenólico da parede celular dos vegetais, normalmente considerada indigestível e também inibidora da digestibilidade da parede celular das plantas forrageiras, acentuando a sua ação, à medida que o vegetal amadurece (Fukushima et al., 2000). Sabe-se que a lignina tem um importante papel no revestimento dos tecidos de transporte de água e nutrientes, sendo responsável pela resistência mecânica de vegetais, além de proteger os tecidos contra o ataque de microrganismos (Saliba et al., 2001). 
A determinação da lignina é feita a partir da análise de FDA (Silva \& Queiroz, 2005; Genro \& Orqis, 2009). Existem diferentes métodos na literatura empregados na avaliação de lignina, entre eles: método da hidrólise ácida, adotada como padrão; lignina com permanganato de potássio; lignina Klason; e lignina solúvel em brometo de acetila. (Hindrichsen et al., 2006). De acordo Detmann et al. (2012), há divergências significativas nos resultados obtidos em laboratórios para todos os métodos aplicados.

Visto isso, Fukushima e Savioli (2001) tentaram eleger o método analítico mais adequado para a estimativa quantitativa da concentração de lignina. Os dados relativos às concentrações de lignina foram obtidos por intermédio do método espectrofotométrico lignina solúvel em brometo de acetila - LSBA (Fukushima, 1996) e, para fins comparativos, dois outros métodos, de natureza gravimétrica, foram conduzidos: o método da lignina detergente ácido - LDA (Van Soest, 1964) e lignina permanganato de potássio - Lper (Van Soest e Wine, 1968). Eles relataram que não houve concordância entre os três métodos, sendo que, no geral, o método da LSBA mostrou valores mais elevados que os outros dois métodos, e o método da LDA menores valores. Em consequência, o procedimento espectrofotométrico revelou potencial para ser empregado na determinação quantitativa da lignina em plantas forrageiras.

O método lignina solúvel em brometo de acetila (LSBA) foi introduzida para a determinação de lignina na madeira por Johnson et al. (1961), e modificações foram feitas para adaptar esse procedimento para vários substratos forrageiros. No entanto, essa abordagem tradicional exigia a extração da lignina com dioxano acidificado e seu isolamento de cada amostra da planta para construir uma curva padrão via análise espectrofotométrica (Fukushima \& Kerley, 2011), porém demorado e tedioso. Por isso, estes autores propuseram simplificar a quantificação de lignina pelo método lignina solúvel em brometo de acetila, extraída de uma variedade de espécies de plantas que tinham características de absorção semelhantes, permitindo assim apenas um extrato de lignina a ser usado como padrão para medir a concentração de lignina nas espécies vegetais. Concluiu-se que a quantificação de lignina pelo uso de uma equação de regressão comum evita as etapas de extração de lignina, isolamento e construção de curvas padrão, o que acelera substancialmente o método LSBA.

Do mesmo modo, Gomes et al. (2011), avaliaram o teor de lignina por diferentes métodos analíticos e sua relação com os parâmetros de degradação da FDN em gramíneas e leguminosas tropicais. O teor de lignina das forrageiras foi quantificado por cinco métodos diferentes: solubilização da celulose por ácido sulfúrico após extração com detergente ácido [Lignina (as)] (Van Soest e Robertson, 1985); oxidação por permanganato de potássio após extração com detergente ácido [Lignina (pp)] (Van Soest e Wine, 1968); método lignina Klason (LK) (Theander e Westerlund, 1986); método da lignina solúvel no brometo de acetila após extração com detergente ácido (LSBAeda) e o método da lignina solúvel no brometo de acetila usando o resíduo da parede celular (LSBApc) (Van Soest \& Wine, 1968). Este estudo mostrou que a contaminação proteica afetou significativamente as estimativas do conteúdo de lignina por todos os métodos gravimétricos. No entanto, essa contaminação foi mais evidente no método LK do que nos métodos Lignina (as) e Lignina (pp). Portanto, a correção de proteínas é sugerida, particularmente para o método da lignina Klason.

\subsection{Digestibilidade}

A digestibilidade é uma medida da proporção do alimento consumido que é digerido e metabolizado pelo animal. Pode ser estimada através de ensaios de digestibilidade in vivo, in situ, in vitro, com base na sua composição químicobromatológica (Carvalho et al., 2007), ou através de ensaios de produção de gases in vitro.

No geral, o método in vivo consiste na utilização de animais em gaiola metabólica. No método in situ utiliza a técnica de incubação de sacos de náilon no animal fistulado, e no método in vitro, equivale a uma técnica laboratorial que é utilizada com finalidade de reproduzir condições do aparelho digestório, simulando o processo de digestão que ocorre no animal (Rech et al., 2010). Entre os métodos, o método in vivo é considerado mais confiável, e são baseados na observação das quantidades 
ingeridas e excretadas das frações de interesse no alimento. Os métodos in situ são técnicas bastante utilizados para estimar a degradação ruminal de nutrientes pela relativa simplicidade e baixo custo quando comparada aos experimentos in vivo. Já o método in vitro, método descrito inicialmente por Tilley e Terry (1963), ainda é a mais utilizada para predição da digestibilidade, simulando a digestão ruminal por 48 horas, seguida por digestão química por 24 horas (Berchielli et al., 2005)

De acordo Gosseling et al. (2004), as experiências in vivo para determinar os valores da digestibilidade das forragens são caras e trabalhosas, prejudicam o bem-estar dos animais e não são adequadas para análises de rotina. Em razão disso, foram desenvolvidas, nas últimas décadas, várias técnicas laboratoriais alternativas (Tilley \& Terry, 1963; Ørskov \& McDonald, 1979; Theodorou et al., 1994), assim como modelos matemáticos baseados na composição bromatológica (McDowell et al., 1974; Weiss et al., 1992), para estimar o valor nutritivo dos alimentos. Além disso, o mercado disponibiliza um fermentador artificial de rúmen, denominado DaisyII (Ankom Technology Corporation, Macedon, NY, EUA), com a vantagem de possibilitar a análise de digestibilidade in vitro de várias amostras simultaneamente, reduzindo-se, assim, o labor empregado nas análises (Holden, 1999).

Dessa forma, Santos et al. (2000) avaliaram as digestibilidades in vitro da MS e da MO de gramíneas do gênero Cynodon com o uso do sistema Daisy ${ }^{\mathrm{II}}$ da Ankom ${ }^{\circledR}$ Technology Corporation em relação ao método tradicional proposto por Tilley e Terry (1963). Foi observado que não houve diferença entre as cultivares quando avaliadas pelo método tradicional. No entanto, com a metodologia Daisy ${ }^{\mathrm{II}}$ houve significância entre as gramíneas do gênero Cynodon. Estes pesquisadores inferiram essas diferenças encontradas com a utilização da metodologia Daisy ${ }^{I I}$ à porosidade dos sacos ou com a proporção da soluçãotampão e inóculo ruminal. A Daisy ${ }^{\mathrm{II}}$ é um sistema efetivo para determinar a DIVMS e DIVMO e fornece dados similares aos encontrados pelo sistema tradicional, no entanto, conforme o alimento testado, podem ocorrer variações nos resultados.

No Brasil, a indústria nacional produziu equipamento com características similares ao Daisy ${ }^{\mathrm{II}}$, a incubadora TE-150 (Tecnal Equipamentos Científicos, Piracicaba, SP, Brasil). Silva et al. (2017) compararam a digestibilidade in vitro da MS (DIVMS) e da fibra em detergente neutro (DIVFDN) de forragens e concentrados obtidos por intermédio das incubadoras Daisy ${ }^{\text {II }}$ e TE-150, combinadas com Filter Bags tipo F57 (Ankon®) ou tecido não tecido (TNT, 100g m²), em relação aos valores obtidos utilizando-se o método de Tilley e Terry (1963). Todos os métodos avaliados apresentaram-se positiva e fortemente correlacionados, tanto com relação à DIVMS como com relação à DIVFDN para forragens e concentrados. Portanto, concluíram que, em se tratando de avaliações comparativas entre alimentos, todos os métodos avaliados possuem capacidade similar de discriminação.

Gosseling et al. (2004) ainda citam como técnicas alternativas da digestibilidade in vivo, a técnica pepsina-celulase, e a técnica de produção de gás. Então estes estudiosos, também determinaram a digestibilidade da MO e MS em forragens, utilizando técnicas da bolsa de náilon in situ (Michalet-Doreau et al., 1987) ajustados ao modelo exponencial de Ørskov e McDonald (1979), a técnica de pepsina-celulase (Aufrère e Michalet-Doreau, 1988), a técnica de Tilley e Terry (1963), e a técnica de produção de gás (Theodorou et al., 1994). A previsão pela técnica in situ mais o conteúdo de PB mostrou maior precisão nas validações, embora as quatro técnicas alternativas tenham mostrado uma potência semelhante na predição da digestibilidade da MO. A escolha da técnica para previsão também depende de outros fatores, como bem-estar animal, preço, tempo, experiência e informações adicionais sobre a degradação dos alimentos.

Similarmente, Silveira et al. (2009) avaliaram a acurácia dos métodos laboratoriais para estimar a digestibilidade e o valor energético de dietas para bovinos de corte. Os valores de digestibilidade medidos in vivo foram comparados com os obtidos nos ensaios in situ, in vitro e in vitro/gases, e com valores estimados a partir de equações matemáticas baseadas na composição química das dietas. Não foi observada interação significativa de dietas versus métodos. Em todos os métodos, as digestibilidades da MS ou da MO aumentaram linearmente com o aumento do nível de concentrado. Contudo, as taxas de degradação calculadas a partir dos ensaios in situ e in vitro/gases não foram acuradas para estimar o valor nutritivo dos 
alimentos, e o método in vitro foi o que melhor estimou a digestibilidade das dietas. As equações matemáticas superestimaram o valor nutricional das dietas por superestimar a digestibilidade da fibra e subestimar a excreção endógena fecal.

Os procedimentos de coleta de fluido ruminal também vem sendo modificados de várias maneiras, na tentativa de reduzir a variabilidade da atividade do inóculo. No entanto, existem poucos dados publicados que documentam quanto e com que consistência essas modificações reduzem a variabilidade de execução para execução dos métodos de digestibilidade in vitro. Nesse sentido, Goeser e Combs (2009) objetivaram determinar se uma técnica de priming de fluido ruminal melhoraria a precisão da digestibilidade in vitro da FDN (DIVFDN) em relação a técnica de Tilley e Terry (1963) modificada por Goering e Van Soest (1970), reduzindo a variação de repetição. As técnicas in vitro descritas neste estudo diferem das de Goering e Van Soest (1970) através das seguintes modificações: uso de um período de incubação de 24 horas, uso de sacos F57 da Ankom® em frascos Erlenmeyer de $125 \mathrm{ml}$ para digestão da FDN, seguidos de lavagem com água destilada à temperatura ambiente foi usado para cessar as fermentaç̃es. Além disso, para o método de preparação, o fluido ruminal foi combinado com solução tampão e solução redutora antes da inoculação, e a celulose foi adicionada à solução de inóculo. A técnica de digestibilidade in vitro da FDN usando fluido ruminal com celulose reduziu o erro entre ensaios da DIVFDN em comparação com uma técnica laboratorial tradicional usando inóculo de um ou dois animais doadores, mas produziu estimativas mais baixas da DIVFDN em $24 \mathrm{~h}$.

Por outro lado, as recomendações para os procedimentos do método da Ankom (Ankom Technology, 2017) sugerem o uso de uma amostra de $0,25 \mathrm{~g}$, mas que um tamanho de amostra de $0,50 \mathrm{~g}$ é aceitável para uma incubação de $48 \mathrm{~h}$. Coblentz et al. (2019) levantaram questões sobre os possíveis efeitos do tamanho da amostra em sacos de fibra selados nas determinações subsequentes da digestibilidade da FDN pelos procedimentos da Ankom. Então testaram os efeitos do tamanho da amostra $(0,25 \mathrm{~g}$ e $0,50 \mathrm{~g})$ na digestibilidade da FDN de forragem triticale pelo procedimento da Ankom® após 12, 24, 30, 48, 144 ou $240 \mathrm{~h}$ de incubação. Eles indicaram que ocorreu maior digestibilidade in vitro das fibras nas amostras de $0,25 \mathrm{~g}$ do que nas amostras de 0,50 g, especialmente após incubações de 24, 30 e 48 h. No geral, a digestibilidade da FDN passou a ser uma variável independente menos eficaz à medida que os tempos de incubação aumentaram.

\subsubsection{Marcadores de digestibilidade}

O uso de marcadores em experimentos é importante para se estimar o consumo e a excreção fecal, especialmente no caso de animais mantidos em sistemas de pastejo, e com base nesses parâmetros determinar a digestibilidade (Salman et al., 2010). Os marcadores são substâncias indigestíveis, normalmente de fácil determinação, podendo ser administradas com o alimento, ou diretamente em algum seguimento do trato digestível, sendo posteriormente identificados e quantificados nas fezes ou ao final do segmento em estudo. A classificação dos mesmos, consiste na divisão entre marcadores internos ou externos (Berchielli et al., 2011).

Os marcadores internos são componentes químicos que ocorrem naturalmente na dieta do animal. Devem ser indigestíveis e quantitativamente recuperáveis nas fezes (Salman et al., 2010). Muitos são os marcadores internos utilizados, em especial a cinza insolúvel em ácido (CIA), cinza insolúvel em detergente ácido (CIDA), lignina em detergente ácido indigestível, fibra em detergente neutro indigestível (FDNi) e fibra em detergente ácido indigestível (FDAi) (Berchielli et al., 2011). Entretanto, tais marcadores exigem longo período de incubação, seja in vivo ou in situ (Van Soest, 1994).

Os marcadores externos, são substâncias indigestíveis fornecidas via oral ou ruminal aos animais. Entre os marcadores externos utilizados em estudos de digestão, o material mais comumente utilizado é oxido crômico $\left(\mathrm{Cr}_{2} \mathrm{O}_{3}\right)(\mathrm{Salman}$ et al., 2010). Mas a literatura ainda cita o Dióxido de Titânio - $\mathrm{TiO}_{2}$ e o LIPE® (Lignina isolada, purificada e enriquecida).

Neste contexto, Ferreira et al. (2009) objetivaram avaliar indicadores internos fibra em detergente neutro indigestível (FDNi) e fibra em detergente ácido indigestível (FDAi), obtidos por incubação in situ durante seis dias, e os indicadores 
externos óxido crômico $\left(\mathrm{Cr}_{2} \mathrm{O}_{3}\right)$, dióxido de titânio $\left(\mathrm{TiO}_{2}\right)$ e lignina isolada, purificada e enriquecida (LIPE ${ }^{\circledR}$ em dois esquemas de coleta total de fezes ( 3 ou 5 dias) para estimativa da digestibilidade em bovinos. Não houve diferença independentemente do indicador utilizado, na digestibilidade da matéria seca determinada com três ou cinco dias de coleta, assim, três dias de coleta são suficientes para estimativa da digestibilidade e os indicadores testados são eficientes na determinação da digestibilidade.

A FDN da forragem consiste em 2 frações: uma fração indigesta (FDNi) e uma fração potencialmente degradável (FDNpd). A fração potencialmente degradável desaparece do rúmen por digestão microbiana, enquanto a fração indegradável de FDN deixa o rúmen apenas por passagem (Mertens, 1993). A FDN indegradável em forragens é comumente determinado como o resíduo da FDN do material que sobra após as incubações in situ ou in vitro. Assim, Bender et al. (2016) objetivaram comparar as estimativas de FDNi com base nas medições in vitro (IV) e in situ (IS) em 2 pontos finais da fermentação (120 e $288 \mathrm{~h}$ ) em silagem de milho. O IV-120 teve uma estimativa mais alta de FDNi (37,8\% da FDN) do que a IS-120 (32,1\% da FDN), IV-288 (31,2\% da FDN) ou a técnica IS-288 (25,7\% da FDN). Verificou-se também que é uma medida robusta entre os métodos de ensaio FDNi, produzindo resultados substancialmente semelhantes, independentemente do método de ensaio.

Como visto anteriormente, têm-se buscado alternativas aos sacos F57 na utilização do sistema Ankom® de análise de fibra, entre essas, o tecido não tecido (TNT), com gramatura $100 \mathrm{~g} \mathrm{~m}^{-2}$. Casali et al. (2009) avaliaram os teores de fibra em detergente neutro indegradável (FDNi) obtidos por procedimento in situ e a perda de partículas fibrosas em meio aquoso de alguns alimentos para ruminantes, utilizando sacos de diferentes tecidos: náilon $(50 \mu \mathrm{m})$; F57 (Ankom®); e TNT (100 g m²). Verificou-se similaridade entre os teores de FDNi obtidos com TNT e F57, que foram superiores aos obtidos com náilon para alguns alimentos do estudo em questão. Houve perda de partículas fibrosas quando empregado o náilon como tecido para avaliação das amostras, o que justifica os menores teores de FDNi obtidos com este tecido. A perda de partículas para o náilon está relacionada à estrutura do tecido, uma vez que, em análise por microscopia eletrônica de varredura, não foram observados danos nos tecidos durante os processos de incubação e extração com detergente.

\section{Considerações Finais}

A correta caracterização da composição química e digestibilidade dos alimentos são imprescindíveis para formulação de dietas balanceadas que possibilitem maximizar a eficiência alimentar, e que consequentemente possam atender os requisitos de mantença e de produção animal. Considerando-se as diversas variáveis que podem ser utilizadas para determinação do valor nutritivo dos alimentos para ruminantes, bem como o avanço e a gama dos métodos analíticos disponíveis na literatura, cabe ao pesquisar adotar aquele que melhor convém ao estudo proposto, levando em consideração o tipo de alimento, custo, disponibilidade de reagentes, materiais, equipamentos, e animais à disposição.

\section{Referências}

Ankom Technology. (2017). In vitro true digestibility using the DAISYII incubator. Ankom Technology Corporation, Macedon, NY. https://www.ankom.com/sites/default/files/document_files/Method_3_Invitro_D200_D200I.pdf.

AOAC International. (1990). AOAC:Official Methods of Analysis. In Arlington, USA: AOAC International, (Vol. 1, Issue Volume 1).

Arzani,, H., Sanaei,, A., Barker,, A. V., Ghafari,, S., \& Motamedi,, J. (2015). Estimating Nitrogen and Acid Detergent Fiber Contents of Grass Species using Near Infrared Reflectance Spectroscopy (NIRS). Journal of Rangeland Science, 5(4), 260-268.

Bender, R. W., Cook, D. E., \& Combs, D. K. (2016). Comparison of in situ versus in vitro methods of fiber digestion at 120 and 288 hours to quantify the indigestible neutral detergent fiber fraction of corn silage samples. Journal of Dairy Science, 99(7), 5394-5400. https://doi.org/10.3168/jds.2015-10258

Berchielli, T. T., Sader, A. P. de O., Tonani, F. L., Paziani, S. de F., \& Andrade, P. de. (2001). Use of the ANKOM system to determine neutral detergent fiber and acid detergent fiber with different filter bags and sample amounts. Revista Brasileira de Zootecnia, 30(5), 1572-1578. http://www.scielo.br/scielo.php?script=sci_arttext\&pid=S1516-35982001000600027\&lng=pt\&nrm=iso\&tlng=pt

Berchielli, T. T., Oliveira, S. G., \& Garcia, A. V. (2005). Application of techniques for intake, diet composition and digestibility studies. Archives of 
Veterinary Science, 10 (2), 29-40.

Berchielli, T. T., Vega-García, A., \& Oliveira, S. G. (2011) Principais técnicas de avaliação aplicadas em estudo de nutrição. In: Berchielli, T. T., Pires, A. V., Oliveira, S. G. Nutrição de Ruminantes. Jaboticabal: Funep, 14 (2), 425-438.

Blaxter, K. L. (1956). The Nutritive Value of Feeds as Sources of Energy: A Review. Journal of Dairy Science, 39 (10), $1396-1424$.

Bortolassi, J. R., Tadeu, G., Alcalde, C. R., Gonçalves, D., Alavarse, M., \& Claudio, A. (2000). Comparação dos métodos convencional e Filter Bag Technique da Ankom ${ }^{\circledR}$ (FBT) para determinação de fibra em detergente neutro e fibra em detergente ácido Comparison of conventional and Ankom's filter bag technique (FBT) methodologies for determining neutral . Acta Scientiarum. Animal Sciences, 22(0), 807-811. https://doi.org/10.4025/actascianimsci.v22i0.3221

Brody. S. (1945). Broenergetrcs and growih. With special reference to the efficiency complex in domestic animals. New York: Reinhold Publishing Corporation. Atlas.

Bueno, A. V. I., Jobim, C. C., Ribeiro, M. G., \& de Oliveira, J. P. (2017). Método de obtenção de matéria seca e composição química de volumosos. Ciência Animal Brasileira, 18, (44913), 1-8.

Campos, P. R. S. S., Valadares Filho, S. C., Detmann, E., Cecon, P. R., Leão, M. I., Lucchi, B. B., Souza, S. M., \& Pereira, O. G. (2010). Consumo, digestibilidade e estimativa do valor energético de alguns volumosos por meio da composição química. Revista Ceres, 57 (1), $79-86$.

Carvalho, P. C. D. F., Kozloski, G. V., Nabinger, C., Ribeiro Filho, H. M. N., Reffatti, M. V., Genro, T. C. M., \& Euclides, V. P. B. (2007). Avanços metodológicos na determinação do consumo de ruminantes em pastejo. Revista Brasileira de Zootecnia. 36, (1)151-170.

Casali, A. O., Detmann, E., Valadares Filho, S. de C., Pereira, J. C., Cunha, M. da, Detmann, K. da S. C., \& Paulino, M. F. (2009). Estimation of fibrous compounds contents in ruminant feeds with bags made from different textiles. Revista Brasileira de Zootecnia, 38(1), 130-138. https://doi.org/10.1590/S151635982009000100017

Cassida, K. A., Turner, K. E., Foster, J. G., \& Hesterman, O. B. (2007). Comparison of detergent fiber analysis methods for forages high in pectin. Animal Feed Science and Technology, 135(3-4), 283-295. https://doi.org/10.1016/j.anifeedsci.2006.07.004

Cecchi, H. M. (2003). Fundamentos teóricos e práticos em análise de alimentos. Campinas: Editora da Unicamp. (2), 1-207.

Coblentz, W. K., Akins, M. S., Ogden, R. K., Bauman, L. M., \& Stammer, A. J. (2019). Effects of sample size on neutral detergent fiber digestibility of triticale forages using the Ankom DaisyII Incubator system. Journal of Dairy Science, 102(8), 6987-6999. https://doi.org/10.3168/jds.2019-16681

Detmann, E., Souza, M. A., Valadares Filho, S. C., Queiroz, A. C., Berchielli, T. T., Saliba, E. O. S., Cabral, L. S., Pina, D. S., Ladeira, M. M., Azevedo, J. A. G. (2012). Métodos para análise de alimentos. Visconde do Rio Branco, MG: Suprema, Atlas.

Farias, J. S., Queiroz, L. O., Santos, G. R. A., Fagundes, J. L., \& Silva, M. A. (2015). Avaliação de tecidos e equipamentos alternativos na análise de fibras em detergente neutro e de fibra em detergente ácido. Boletim de Indústria Animal, 72(3), 229-233. https://doi.org/10.17523/bia.v72n3p229

Ferreira,, M. de A., Filho,, S. de C. V., Marcondes, M. I., Paixão, M. L., Paulino, M. F., \& Valadares, R. F. D. (2009). Avaliação de indicadores em estudos com ruminantes: Digestibilidade. Revista Brasileira de Zootecnia, 38(8), 1568-1573. https://doi.org/10.1590/S1516-35982009000800022

Fontaneli, R. S., Durr, J. W., Scheffer-Basso, S. M., Haubert, F., \& Bortolini, F. (2002). Validação do método da reflectância no infravermelho proximal para análise de silagem de milho. Revista Brasileira de Zootecnia, 31(2), 594-598. https://doi.org/10.1590/s1516-35982002000300008

Fontaneli, R. S., Fontaneli, R. S., Dürr, J. W. Qualidade e valor nutritivo de forragem. In Fontaneli, R.S., Santos, H.P., Fontaneli, R.S. (2012). Forrageiras para integração lavoura-pecuária-floresta na região sul-brasileira, (2), 27-49.

Fukushima, R. S. (1996). Extração da lignina através do brometo de acetila e seu emprego objetivando avaliação quantitativa da lignina de plantas. In: Reunião Anual da Sociedade Brasileira de Zootecnia, Fortaleza, CE. Anais... Fortaleza: SBZ, 33 (3), 318-320.

Fukushima, Romualdo S., \& Kerley, M. S. (2011). Use of lignin extracted from different plant sources as standards in the spectrophotometric acetyl bromide lignin method. Journal of Agricultural and Food Chemistry, 59(8), 3505-3509. https://doi.org/10.1021/jf104826n

Fukushima, Romualdo Shigueo, Garippo, G., Habitante, A. M. Q. B., \& Lacerda, R. S. (2000). Extração da Lignina e Emprego da Mesma em Curvas de Calibração para a Mensuração da Lignina em Produtos Vegetais. Revista Brasileira de Zootecnia, 29(5), 1302-1311. https://doi.org/10.1590/s151635982000000500007

Fukushima, Romualdo Shigueo, \& Savioli, N. M. de F. (2001). Correlação entre digestibilidade in vitro da parede celular e três métodos analíticos para a avaliação quantitativa da lignina. Revista Brasileira de Zootecnia, 30(2), 302-309. https://doi.org/10.1590/s1516-35982001000200002

Galvani, F., \& Gaertner, E. (2006). Adequação da Metodologia Kjeldahl para determinação de Nitrogênio Total e Proteína Bruta. Circular Técnica, 4, 1-9.

Genro,, T. C. M., \& Orquis,, M. G. (2009). Informações básicas sobre coleta de amostras e principais análises químico- bromatológicas de alimentos destinados à produção de ruminantes.

Geron, L. J. V., Cabral, L. S., Trautmann-Machado, R. J., Zeoula, L. M., Oliveira, E. B., Garcia, J., Golçalves, M. R., \& Aguiar, R. P. S. (2014). Avaliação do teor de fibra em detergente neutro e ácido por meio de diferentes procedimentos aplicados às plantas forrageiras. Semina: Ciências Agrárias, 35 (3), 15331542 .

Gindri, M., Zilio, E. M. C., Guterres, A. S., Gindri, R. G., Campos, F. S., Bomfim, M. A. D., Galvani, D. B., \& Kozloski, G. V. (2019). Comparison of methods to estimate crude protein and digestible organic matter content of diets ingested by free-ranging sheep. Small Ruminant Research, 178 (1) $37-42$.

Goering, H. K., \& Van Soest, P. J. (1970). Forage fiber analyses, apparatus, reagents, procedures and some applications. Washington, DC: USDA (USDA. 
Agricultural handbook, 379).

Gomes, D. I., Detmann, E., Valadares Filho, S. de C., Fukushima, R. S., de Souza, M. A., Valente, T. N. P., Paulino, M. F., \& de Queiroz, A. C. (2011). Evaluation of lignin contents in tropical forages using different analytical methods and their correlations with degradation of insoluble fiber. Animal Feed Science and Technology, 168(3-4), 206-222. https://doi.org/10.1016/j.anifeedsci.2011.05.001

Gonçalves, L. C., Borges, I., \& Ferreira, P. D. S. (2009). Alimentação de gado de leite. Belo Horizonte: FEPMVZ.

Gosselink, J. M. J., Dulphy, J. P., Poncet, C., Jailler, M., Tamminga, S., \& Cone, J. W. (2004). Prediction of forage digestibility in ruminants using in situ and in vitro techniques. Animal Feed Science and Technology, 115(3-4), 227-246. https://doi.org/10.1016/j.anifeedsci.2004.01.008

Grana, A. L. Análise de alimentos. (2014). Ave-Porc Nutri. https://aveporcnutri.wixsite.com/aveporcnutri/single-post/2014/01/19/An\%C3\%A1lise-dealimentos.

Guimarães, D. O., Da Silva Momesso, L., \& Pupo, M. T. (2010). Antibióticos: Importância terapêutica e perspectivas para a descoberta e desenvolvimento de novos agentes. Quimica Nova, 33(3), 667-679. https://doi.org/10.1590/S0100-40422010000300035

Hindrichsen, I. K., Kreuzer, M., Madsen, J., \& Bach Knudsen, K. E. (2006). Fiber and lignin analysis in concentrate, forage, and feces: Detergent versus enzymatic-chemical method. Journal of Dairy Science, 89(6), 2168-2176. https://doi.org/10.3168/jds.S0022-0302(06)72287-1

Hristov, A. N., Mertens, D., Zaman, S., Vander Pol, M., \& Price, W. J. (2010). Variability in feed and total mixed ration neutral detergent fiber and crude protein analyses among commercial laboratories. Journal of Dairy Science, 93(11), 5348-5362. https://doi.org/10.3168/jds.2010-3333

Holden, L. A. (1999). Comparison of methods of in vitro dry matter digestibility for ten feeds. Journal of dairy science, 82 (8), $1791-1794$.

Johnson, D. B., Moore, W. E., \& Zank, L. C. (1961). The spectrophotometric determination of lignin in small wood samples. TAPPI, 44 (1), $793-798$.

Keeney D. R., \& Bremner J. M. (1967). Use of the Coleman model 29 A analyser for total nitrogen analysis of soils. Soil Science, 104 (5), $358-363$.

Kleiber, M. (1975). The Fire of Life: An Introduction to Animal Energetics. New York: Robert E. Krieger Publishing Company, 2 (1) 453.

Komarek, A. R. (1993). An improved filtering technique for the analysis of neutral detergent fiber and acid detergent fiber utilizing the filter bag technique. Publication No. 101, Ankom Technology, Fairport, NY.

Lacerda, M. J. R., Freitas, K. R., \& da Silva, J. W. (2009). Determining forage dry matter using microwave oven and conventional method. Bioscience Journal, 25(3), 185-190.

Malavolta, E., Vitti. G. C., \& Oliveira, S. A., (1997). Avaliação do estado nutricional das plantas: princípios e aplicações. Associação Brasileira para Pesquisa da Potassa e do Fosfato, 2 (1), 319.

McDowell, L. R., Conrad, J. H., Harris, L. E., \& Thomas, J. E. (1974). Tabelas de composição de alimentos da América Latina. Flórida, US: Universidade da Flórida.

Mertens, D. R. (1993). Rate and extent of digestion. In: Dijkstra, J., Forbes, J. M., France, J. (Ed.). Quantitative Aspects of Ruminant Digestion and Metabolism., CAB International, Oxon, UK.

Mertens, D. R. (2002). Gravimetric determination of amylase-treated neutral detergent fiber in feeds with refluxing in beakers or crucibles: collaborative study. Journal of AOAC international, 85 (6), 1217-1240.

Michalet-Doreau, B., Vérité, R., \& Chapoutot, P. (1987). Méthodologie de mesure de la dégradabilité in sacco de l'azote des aliments dans le rumen. Bull. Tech. CRZV Theix, 69 (1), 5-7.

Mott, G., \& Moore, J. E. (1970). Forage evaluation techniques in perspective. IN: National Conference on Forage Evaluation and Utilization. Nebraska Center of Continuing Education. Lincoln, Nebraska.

Nogueira, A. R. A., \& Souza, G. B. (2005). Manual de Laboratórios: Solo, Água, Nutrição Vegetal, Nutrição Animal e Alimentos. São Carlos: Embrapa Pecuária Sudeste.

Oliveira, J. A. M., Macedo, A. D. B. de, Raulino, J. L. C., Raulino, A. de M. D., Santana, R. A. C. de, \& Campos, A. R. N. (2015). Determinação do Teor de Água de Cactáceas pelos Métodos Padrão em Estufa e Micro-Ondas. Blucher Chemistry Proceedings, 3(1), 1027-1037. https://doi.org/10.5151/chenpro-5erqeng 16

Ørskov, E. R., \& McDonald, I. (1979). The estimation of protein degradability in the rumen from incubation measurements weighted according to rate of passage. The Journal of Agricultural Science, 92 (2), 499-503.

Ortega-Aguirre, C.A., Lemus-Flores, C., Bugarin-Prado, J.O., Alejo-Santiago, G., Ramos-Quirarte, A., Grageola-Nuñez, O., \& Bonilla-Cardenas, J.A. (2015). Características agronómicas, composición bromatológica, digestibilidad y consumo animal en cuatro especies de pastos de los generos brachiaria y panicum. Tropical and Subtropical Agroecosystems, 18 (1), 291 - 301.

Pazdiora, R. D., Pazdiora, B. R. C. N., Ferreira, E., Muniz, I. M., Andrade, E. R., Siqueira, J. V. S., Sherer, F., Venturoso, O. J., \& Souza, P. J. (2019). Digestibilidade, comportamento ingestivo e desempenho de ovinos alimentados com resíduos de agroindústrias processadoras de frutas. Arquivo Brasileiro de Medicina Veterinária e Zootecnia, 71 (6), 2093-2102.

Phillips, W. A., Starks, P. J., Glasgow, S., \& Coleman, S. W. (2007). Different Methods of Estimating Crude Protein Concentration of Bermudagrass Pastures for Stocker Calf Production1. Professional Animal Scientist, 23(6), 696-701. https://doi.org/10.15232/S1080-7446(15)31042-1

Raffrenato, E., \& Van Amburgh, M. E. (2011). Technical note: Improved methodology for analyses of acid detergent fiber and acid detergent lignin. Journal 
of Dairy Science, 94(7), 3613-3617. https://doi.org/10.3168/jds.2010-3701

Rech, C. L. S., Rech, J. L., Pires, A. J. V., Nunes, G. S., Figueiredo, M. P., Xavier, E. G., Pino, F. A. B., Roll, V. F. B., Aguiar, L. V., Meira, A. N, \& Costa, L. S. (2010). Manual prático de análises de alimentos para animais de interesse zootécnico. UESB.

Rodrigues, M. T., Vieira, R. A. M. (2011). Metodologias aplicadas ao fracionamento de alimentos. In: Berchielli, T.T., Pires, A.V., Oliveira, S.G. Nutrição de Ruminantes. 2. ed. Jaboticabal: Funep.

Saliba, E. de O. S., Rodriguez, N. M., Morais, S. A. L. de, \& Piló-Veloso, D. (2001). Ligninas: métodos de obtenção e caracterização química. Ciência Rural, 31(5), 917-928. https://doi.org/10.1590/s0103-84782001000500031

Salman,, A. K. D., Ferreira,, A. C. D., Soares,, J. P. G., \& Souza,, J. P. de. (2010). Metodologias para avaliação de alimentos para ruminantes domésticos (Vol. 1).

Santos,, G. T. dos, Assis, M. A. De, Gonçalves, G. D., Modesto, C., Cecato, U., Cabreira, C., \& César, J. (2000). Determinação da digestibilidade in vitro de gramíneas do gênero Cynodon com uso de diferentes metodologias. Acta Scientiarum. Animal Sciences, 22(3), 761-764. https://doi.org/10.4025/actascianimsci.v22i0.3187

Serafim,, R. S., Antonelli,, A., \& Santos,, M. A. T. (2017). Determinação Da Matéria Seca E Proteína Bruta Pelo Método Convencional E Microondas. Zootecnia Animal Science, 1(1139-43).

Silva,, D. J., \& Queiroz,, A. C. de. (2005). Análise de Alimentos: Métodos Químicos e Biológicos.

Silva, T. E., Detmann, E., Camacho, L. F., Saliba, E. O. S., Palma, M. N. N., \& Filho, S. C. V. (2017). Comparação de métodos in vitro para a quantificação da digestibilidade da matéria seca e da fibra em detergente neutro de forragens e concentrados. Arquivo Brasileiro de Medicina Veterinaria e Zootecnia, 69(6), 1635-1644. https://doi.org/10.1590/1678-4162-9096

Silveira, M. F., Kozloski, G. V., Mesquita, F. R., Farenzena, R., Senger, C. C. D., \& Brondani, I. L. (2009). Avaliação de métodos laboratoriais para estimar a digestibilidade e o valor energético de dietas para ruminantes. Arquivo Brasileiro de Medicina Veterinaria e Zootecnia, 61(2), 429-437. https://doi.org/10.1590/S0102-09352009000200021

Souza,, G. B. de, Nogueira,, A. R. de A., Sumi,, L. M., \& Batista,, L. A. R. (1999). Método Alternativo para a Determinação de Fibra em Detergente Neutro e Detergente ácido.

Souza, M. A. de, Detmann, E., Batista, E. D., Franco, M. de O., Valadares Filho, S. de C., Pina, D. S., \& Rocha, G. C. (2017). Estudo colaborativo para avaliação dos teores de matéria mineral em alimentos. Revista Brasileira de Saúde e Produção Animal, 18(1), 62-75. https://doi.org/10.1590/s151999402017000100007

Theander, O., \& Westerlund, E. A. (1986). Studies on dietary fiber. 3. Improved procedures for analysis of dietary fiber. Journal of Agricultural and Food Chemistry, 34 (2), 330-336.

Theodorou, M. K., Williams, B. A., Dhanoa, M. S., Mcallan, A. B., \& France, J. (1994). A simple gas production method using a pressure transducer to determine the fermentation kinetics of ruminant feeds. Animal Feed Science and Technology, 48 (3-4), 185-197.

Tilley, J. M. A., \& Terry, R. A. (1963). A two-stages technique for the in vitro digestion of forage crop. Journal of British Grassland Society, 18 (2), $104-111$.

Van Soest, P. J. (1964). Symposium on nutrition and forage and pastures: new chemical procedures for evaluating forages. Journal of Animal Science, 23 (3), 838-845.

Van Soest, P. J., \& Wine, R. H. (1968). The determination of lignin and cellulose in acid-detergent fibre with permanganate. Journal Association of Official Analytical Chemists. (51), 780-785.

Van Soest, P. J., \& Robertson, J. B. (1985). Analysis of Forages and Fibrous Foods. Cornell University Press, Ithaca.

Van Soest, P. J., Robertson, J. B., \& Lewis, B. A. (1991). Methods for dietary fiber, neutral detergent fiber, and nonstarch polysaccharides in relation to animal nutrition. Journal of dairy science, 74 (10), 3583-3597.

Van Soest, P. J. (1994). Nutritional ecology of the ruminant. (2a ed.), Cornell University Press.

Weiss, W. P., Conrad, H. R., \& Pierre, N. R. (1992). A theoretically-based model for predicting total digestible nutrient values of forages and concentrates. Animal feed science and technology, 39 (1), 95-110. 